\title{
A LAÏCITÉ EM QUESTÃO. UM COMENTÁRIO A UM TEXTO DE LUCA DIOTALLEVI.
}

Ari Pedro Oro ${ }^{1}$

Claude Petrognani ${ }^{2}$

O tema da laicidade, e da secularização, seu equivalente próximo, constituem objetos bastante controversos e polêmicos nas Ciências Sociais. Isso porque, como assinala Jeffrey Hadden (1987), mais do que teorias, aqueles conceitos representam uma doutrina e mesmo uma ideologia, ou, como sustenta Pierre Sanchis, pode-se tratar de um projeto e, até mesmo, de desejos pessoais. Assim expressa-se este último autor: "Talvez não haja nas Ciências Sociais outro campo em que os analistas investem com mais intensidade os desejos frutos de histórias de vida conflituais - nos sentidos, aliás, os mais inesperados" (Sanchis, 2001, p. 31).

Evidentemente que nada disso se aplica diretamente ao texto de Diotallevi aqui comentado, o qual é bastante cuidadoso nas suas afirmações, fino em sua análise e perspicaz em suas considerações teóricas. Além disso, Diotallevi demonstra deter um amplo domínio de conhecimento sobre o tema da laicidade e das teorias construídas sobre ela. Basta ver a ampla bibliografia utilizada para escrever esse texto, o qual, neste sentido, consiste numa contribuição importante para o público de língua portuguesa que deseja se debruçar sobre o tema e que, muitas vezes, possui dificuldade para acessar a ampla literatura internacional existente sobre ele.

1 Professor titular do Departamento de Antropologia e do Programa de Pós-Graduação em Antropologia Social da Universidade Federal do Rio Grande do Sul. Contato: arioro@uol.com.br

2 Doutorando do Programa de Pós-Graduação em Antropologia Social da Universidade Federal do Rio Grande do Sul. Objeto da tese: as relações entre futebol e religião. Contato: claude.petrognani@libero.it

Debates do NER, Porto Alegre, Ano i6, N. 27, P. 5I-6I, JAn./Jun. 2015 
Nesse seu texto sobre "o separatismo moderado", Diotallevi ocupa-se da religião no espaço público analisando dois modos de separatismo, o francês da laicidade e o norte-americano da liberdade religiosa. Em ambos, são analisadas as relaçóes vigentes entre os poderes político, religioso e jurídico. Para tanto, seu estudo vale-se da teoria de Luhmann como aporte para compreender a atualidade das relaçōes entre esses poderes.

Nosso comentário sobre o texto de Diotallevi incide sobre uma única questão: a laïcité francesa. Não para polemizar com o autor, mas, tão somente, para produzir algumas relativizações, introduzir alguns questionamentos e, eventualmente, avançar em algumas afirmações sobre esse tema. Produzimos nossas considerações apoiados nas análises realizadas pelo sociólogo francês Jean Baubérot, autor de vários textos sobre a laicidade. Assim procedendo, temos consciência, porém, de que pesa sobre as nossas próprias consideraçōes o questionamento acerca da unilateralidade da abordagem e da perspectiva, mesmo nos apropriando das ideias de um dos maiores especialistas franceses sobre o tema da laicidade ${ }^{3}$.

\section{A laicidade francesa Na visÃo de Jean Baubérot}

Escreve Luca Diotallevi a propósito da lä̈cité: “[...] no âmbito do separatismo radical, a laïcité acaba representando não apenas uma exceção na exceção, mas também uma exceção em crise. É isto que ao final, de comum acordo, testemunham os seus críticos e os seus defensores" (Diotallevi, 2014, p. 3), exceto, como esclarece numa nota de rodapé, "posições extremas e isoladas" (Diotallevi, 2014, p. 4), referindo-se ao texto de Jean Baubérot Le tante laicità del mondo (2008), tradução do livro Les lä̈cités dans le monde (2007).

3 Elencamos alguns livros de Jean Baubérot sobre a laicidade: Laicité 1905-2005, entre passion et raison. Paris: Seuil, 2004; Les laücités dans le monde. Paris: PUF, 2007; La laücité falsifiée. Paris: La découverte, 2012; Histoire de la lä̈cité en France. Paris: PUF, 2010; Baubérot, J.; Milot, M. Lä̈cités sans frontières. Paris: Seuil, 2011.

Debates do NER, Porto Alegre, Ano i6, N. 27, P. 5I-6I, JAn./Jun. 2015 
De fato, neste texto, assim como em tantos outros, Baubérot, considerado uma referência incontornável sobre o tema da lä̈cité $^{4}$, sustenta que "A laïcité não é uma exceção francesa" (Baubérot, 2007, p. 119), apoiando-se em fatos históricos precisos e incontestáveis.

Em relação à crise da lä̈cité francesa, vale indagar-se até que ponto ela decorre, como sugere Diotallevi, do fato de que na lä̈cité o espaço público resulta "[...] homogêneo e dominado pelo poder político [...] colocando a religião no privado" (Diotallevi, 2014, p. 5), enquanto, no caso da religious freedom, o espaço público resulta, pelo contrário, "[...] heterogêneo e subtraído de cada hegemonia [...] assegurando um espaço público para a religiāo" (Diotallevi, 2014, p. 5).

Ora, em Paris (como em Nova Iorque), o espaço público constitui-se heterogêneo: mesquitas, templos, igrejas, catedrais e sinagogas estão espalhadas pela cidade. Seria suficiente, por exemplo, passear pelo bairro Le Marais, na capital francesa, para se dar conta das inúmeras lancherias hebraicas servindo os falafel e pessoas perambulando vestindo o kipá. E o que dizer da maravilhosa mesquita situada na rive gauche, próxima do famoso bairro Quartier Latin e das inúmeras mulheres vestindo a hijab?

De fato, como veremos num segundo momento, sempre seguindo as análises de Baubérot, a lä̈cité francesa, assim como é expressa na lei da separação de 1905, lei que Baubérot considera como "a regra de ouro da laicidade francesa" (Baubérot, 2011, p. 63), não prevê a atuação e o domínio do Estado no espaço público, relegando (como parece sustentar Diotallevi) a religião à esfera do privado.

O fundamento da separação Igreja/Estado na França (assim como nos Estados Unidos) repousa na construção de uma sociedade civil na qual as pessoas de diferentes religiōes e crenças podem conviver pacificamente, uma

4 Vale recordar que, para este sociólogo francês, a laicidade "implica a dissociação do campo político (como instância do poder) e do campo religioso (como instância da autoridade), a autonomia do político na regulação normativa de uma sociedade pluralista, especialmente em relação ao plano jurídico" (Baubérot, 2010, p. 621).

Debates do NER, Porto Alegre, ano i6, N. 27, P. 5I-6I, JAN./Jun. 2015 
sociedade laica na qual o Estado garante as mesmas liberdades e direitos a todos. Assim, a laïcité “[...] é um conceito insubstituível"” (Baubérot, 2011), que não limita as liberdades, mas, pelo contrário, as sustenta e as amplia: “[...] a liberdade laica está atenta não só em relação à liberdade de religião, mas também à liberdade da religião" (Baubérot, 2011, p. 59, grifo do autor).

Segundo Baubérot, quando a política, em nome da "sacralidade" da laïcité, aprova lei restritiva como aquela que proíbe os alunos de exibirem marcas vistosas de seu pertencimento religioso nas escolas (2004), ou as mulheres de vestirem em público a burqa (2010), ela (a política) está fazendo uma interpretação ilegítima da lei de 1905, falsificando-a (Baubérot, 2012), estigmatizando, assim, com fins políticos, em particular uma religião, o Islamismo.

\section{A "LAÏCITÉ", UMA EXCEÇÃO FRANCESA?}

Esta fórmula: "La laïcité é uma exceção francesa”, adotada na França no final dos anos 1980 (Baubérot recorda que foi em 1989, por ocasião de um seminário cujo título era: "a laicidade, uma exceção à francesa", em que ela foi adotada pela primeira vez), tornou-se tão evidente e de domínio comum, para os franceses, mas não somente para eles, que, como escreve ironicamente o sociólogo francês, "[...] fez escrever coisas erradas por pessoas que pretendiam ter autoridade no assunto" (Baubérot, 2007, p. 119). Exemplo: em 2007, o Haut Conseil à l'intégration escreve que "[...] objeto de espanto para todos, a lei da separação (de 1905) provocou emulações e fez nascer imitações" (Baubérot, 2011, p. 120), indicando o caso do México. Isso é falso, pois, no México, a lei da separação foi estabelecida em 1861 e acentuada em 1874. Portanto, não resulta que tenha sido o México a ter imitado a França,

5 Escreve Baubérot (2011): "As laicidades possuem em comum o fato de articular quatro princípios [...] a garantia da liberdade de consciência, a igualdade e a não-discriminação, a separação do político e do religioso, a neutralidade do Estado no que diz respeito às diferentes crenças. O termo läcité é portanto insubstituível”. Disponível em: <jeanbauberotlaicite.blogspirit.com>. Acesso em: 8-9 nov. 2014.

Debates do NER, Porto Alegre, Ano i6, N. 27, P. 5I-6I, JAN./Jun. 2015 
mas, muito pelo contrário, “[...] bem longe de imitar a França, o México constituiu uma referência na elaboração da lei francesa da separação da Igreja e do Estado" (Baubérot, 2011, p. 120), como é documentado também na relação da "Commission parlementaire", redigida por Aristide Briand, o qual cita longamente a lei da separação mexicana de 1874: "O México possui portanto a legislação laica mais completa e que nunca foi implementada até hoje. Liberou-se depois de trinta anos da questão clerical e pôde se dedicar inteiramente a seu desenvolvimento econômico: ele conhece realmente a paz religiosa" (Baubérot, 2011, p. 120).

Além disso, Briand recorda que a França, adotando a lei da separação de 1905, simplesmente juntou-se a um grupo de países que já haviam adotado a lei da separação Igreja/Estado, a saber: o Canadá, os Estados Unidos, o Brasil e o México (Baubérot, 2011, p. 120).

De fato, operando a separação, em 1905, entre Igreja/Estado, a França "[...] limita-se a alcançar este terceiro grupo onde vários países já a precederam. Estamos no oposto de uma visão da laïcité excepcional" (Baubérot, 2011, p. 120).

Assim sendo, é válido questionar até que ponto, como parece assumir Diotallevi, pode-se referir à laicidade como uma "exceção francesa".

\section{A “LAÏCITÉ", DOMÍNIO DO ESTADO NO ESPAÇO PÚBLICO?}

No artigo Liberdade religiosa e laicidade francesa, Baubérot (2011), depois de realizar uma rápida reconstrução histórica da laïcité francesa, apresenta e comenta a famosa lei da separação de 1905. Trata-a como uma "regra de ouro", como já referimos anteriormente, considerando-a o fundamento jurídico principal da laicidade francesa (Baubérot, 2011, p. 64).

Procedendo a uma rápida análise dos artigos e das emendas principais constitutivos da lei de 1905, o autor percebe que, de fato, não se tratava de uma restrição/exclusão das religiōes do espaço público, mas, ao contrário, a mesma lei permitiu às religiōes minoritárias de adquirirem uma maior visibilidade. Aliás, como veremos em seguida, o Islamismo pôde se beneficiar da lei de 1905.

Debates do NER, Porto Alegre, ano i6, N. 27, P. 5I-6I, JAN./Jun. 2015 
De fato, como sublinha Baubérot (2011, p. 64), "Aspectos desta lei demonstram que (esta) é politicamente liberal e razoável de um ponto de vista religioso". Os artigos XII e XVII da lei de 1905, que regulam a distribuição dos edifícios religiosos (propriedade pública depois da Revolução Francesa, ou construídos no século XIX com financiamento público ${ }^{6}$ ), concedem gratuitamente estes espaços de culto (uma emenda querendo introduzir o pagamento de um aluguel foi rejeitada por 475 votos contra 95); o artigo II especifica que o poder público pode dispensar os gastos relativos a serviços de caridade e facilitar o livre exercício de culto; a proposta de uma emenda para substituir o calendário das festas religiosas foi rejeitada (por 466 votos contra 60); da mesma forma, uma emenda que queria tornar obrigatória a cidadania francesa para alguém se tornar ministro de culto também foi rejeitada (por 460 votos contra 60); uma emenda que pretendia proibir a utilização da talare (típico traje eclesiástico) no espaço público foi também rejeitada (por 391 votos contra 184); foi confirmada a liberdade de procissão (de religião e da religião) no espaço público (artigo 31). Por último, como recorda Baubérot (2011), a lei da separação de 1905 não foi aplicada nas colônias $^{7}$ nem nas regiões da Alzacia e Mosella, onde, por razões históricas ${ }^{8}$ permaneceu (até hoje) a concordata de 1801.

Como mencionado anteriormente, o Islamismo também se beneficiou da lei de 1905. Recorda Baubérot que na França, atualmente, o Islamismo tornou-se a segunda religião, depois do catolicismo, e, apesar da falta de estatísticas oficiais sobre o número de muçulmanos, "O número estimado

6 A saber, a maioria das igrejas católicas, cerca da metade dos templos protestantes e um terço das sinagogas (Baubérot, 2011, p. 64).

$7 \mathrm{Na}$ Argélia, por exemplo, permanecerá uma política gallicana, apesar das reivindicaçōes dos argelinos para que o Islamismo se beneficiasse da lei de 1905 (Bozzo, 2006, apud Baubérot, 2011, p. 65).

8 Sabe-se que as regiōes da Alzacia e da Mosella, que em 1871 se tornaram alemãs, retornaram ao domínio francês em 1919, e que a lei de laicização da escola pública (a lei Ferry, de 1882) e a lei da separação Igreja/Estado, de 1905, não foram aplicadas (Baubérot, 2011, p. 65). 
dos muçulmanos na França metropolitana pode variar de 2,1 milhōes (Ined) até $5 / 6$ milhões de muçulmanos, dos quais 20/25\% seriam praticantes" (Baubérot, 2011, p. 66).

Nos anos 20 do século XX, portanto quinze anos depois da adoção da lei de separação de 1905, calculava-se que o número de muçulmanos na França não alcançava mais do que 150.000 pessoas $^{9}$, mas, apesar disso, comenta Baubérot (2011, p. 65), "[...] uma grande mesquita foi construída em Paris e a construção beneficiou de subsídios públicos”.

Aos que protestaram em nome da lei de 1905, porque violaria o artigo II, que afirma que "[...] a República não reconhece, não sustenta, nem subsidia culto algum” (Baubérot, 2011, p. 63), foi respondido que a decisão de subsidiar a construção da mesquita aplicava simplesmente o princípio da igualdade entre as várias religiōes, dispositivo este também constante na lei de 1905. A este respeito escreve Baubérot (2011, p. 65) que "Edouard Herriot, personalidade laica, considerado muito rígido", declarou: “[...] não há impedimento algum em dar aos muçulmanos uma mesquita no momento em que legitimamente damos aos católicos, igrejas, aos protestantes, templos, e aos hebreus, sinagogas" (Poulat, 2003, p. 185 apud Baubérot, 2011, p. 65).

Esta interpretação da lei de 1905 continuou a prevalecer e, apesar das numerosas contestaçôes e tentativas de bloquear novas construçôes de mesquitas, o número das mesmas cresceu acompanhando o aumento da população muçulmana. Baubérot (2011, p. 66) especifica que hoje em dia a França possui noventa mesquitas e que uma centena delas está sendo construída, além de existir 2.368 centros de orações.

O Conselho de Estado propôs, em 19 de julho de 2011, para mediar estes dois aspectos da lei de 1905 (artigo II) - aquele que proíbe o poder público de financiar cultos e aquele que garante o direito de praticá-los - a construção de "salas polivalentes, uma delas servindo às cerimônias do culto muçulmano, à condição de não ser nem exclusiva nem perpétua" (Baubérot, 2011, p. 66).

9 Disponível em: <www.wikipedia.org/wiki/Islam_en_France>. Acesso em: 8-9 nov. 2014. 
Além disso, o Conselho de Estado estabeleceu que os subsídios públicos não violam o artigo II: de fato, é fixada uma distinção entre o cultual (que não pode ser subsidiado) e o cultural (que pode ser subsidiado). Isso faz com que os subsídios públicos aqui em jogo sirvam para o bem comum (cultural) e não para um culto particular (cultual): "[...] o Conselho de Estado autoriza subsídios públicos para a construção de um elevador numa igreja católica, invocando um interesse público [...] assim como autoriza o financiamento de um matadouro da carne halal, por razôes de higiene e saúde pública" (Baubérot, 2011, p. 67). Trata-se, portanto, de uma aplicação moderada da lei de 1905 que está conforme a jurisprudência (Baubérot, 2011, p. 66) ${ }^{10}$.

A partir dessas considerações, não parece haver, portanto, na lei da separação de 1905, algo que possa dizer que a separação Igreja/Estado foi realizada na França para excluir as religiōes do espaço público.

Além disso, vale recordar, por exemplo, que o campo da educação, na França, é também heterogêneo: de fato, aqui também não há o domínio do Estado no espaço público: sabe-se que ao lado das escolas públicas e laicas (a lei da laicização da escola pública de J. Ferry é datada de 1882), temos as escolas confessionais (católicas, hebraicas e muçulmanas), as quais, sem receber subsídio do Estado ${ }^{11}$, podem exercer a educação conforme o próprio credo religioso. Baubérot recorda que a introdução da lei de 2004 (que analisaremos em seguida) proporcionou o aumento de jovens judeus nas escolas confessionais israelitas que utilizam o kipá (Baubérot, 2011, p. 68). Isto fez com que o número de escolas muçulmanas também crescesse (Id., Ibid.).

${ }^{10}$ O Conselho de Estado relembrou também que depois da lei de 1905 foram construídas, seguindo o item acima mencionado, cerca de 450 igrejas católicas.

${ }^{11}$ Contudo, sabe-se que há escolas privadas (confessionais ou não) que podem receber subsídios do Estado, desde que assinem um contrato. Disponível em: <www.education. gouv.fr>. Acesso em: 8-9 nov. 2014.

Debates do NER, Porto Alegre, Ano i6, N. 27, P. 5I-6I, JAn./Jun. 2015 
Portanto, a lä̈cité, assim como a sustenta Baubérot, não produziu uma separação entre Igreja/Estado, na qual o poder político confinaria as religiōes na esfera do privado. Ou seja, dito de maneira diferente, não parece ter havido uma subordinação do religioso ao político no espaço público, tese esta bastante recorrente, que Diotallevi também parece acatar.

Todavia não podemos negar que a lei votada em $2004^{12}$ (dita "lei da laicidade", 15/03/2004, que reduziu, como diz Baubérot (2011, p. 67), "[...] na visão de alguns, a laicidade a somente esta questão"), ao proibir os alunos de ostentarem na escola símbolos vistosos de pertencimento religioso, assim como a lei de 2010 (imposta em nome da "ordem pública" e não da "laicidade"), ao proibir o uso do foulard integral (burqa ou niqab) no espaço público, dão razão a Diotallevi. De fato, as leis de 2004 e de 2010 instauraram um controle do Estado sobre as religiōes, proibindo e sancionando certas práticas religiosas.

Baubérot, no seu livro La lä̈cité falsifiée (2012), procura demonstrar, porém, que a laicidade, assim como é estabelecida nas leis de 2004 e de 2010, é uma impostura, uma falsificação que, pelo contrário, fere o espírito e os princípios da lä̈cité constantes na lei de 1905.

Numa entrevista ao jornal La Croix ${ }^{13}$ (em 10 de fevereiro de 2012), Baubérot afirma:

Vê-se, assim, aparecer o que eu chamo, seguindo François Baroin, uma 'nova laicidade', sinônimo de um controle do Estado sobre a religião e de repressão em relação a tudo o que foge deste controle. Esta laicidade não parece ser a nossa 'laicidade histórica', cuja lei de 1905 fixou o quadro. É esta impostura histórica e simbólica que eu quis desmontar. A lei de 1905 estabelece que a religião não é affaire do Estado, e que ela deve ser distinta da potência pública. Mas isto não significa que a religião seja confinada na 'esfera íntima'. Ao

12 A Comissão Stasi (2004) redigiu um relatório sobre a laicidade, a qual produziu 26 proposiçōes, entre as quais, a mais controversa, concerne a "lei de laicidade" (Baubérot, 2011, p. 67).

${ }^{13}$ Disponível em: <www.la-croix.com/Debats/Opinions/Debats/Jean-Bauberot>. Acesso em: 2 out. 2012.

Debates do NER, Porto Alegre, ano i6, N. 27, P. 5I-6I, JAn./Jun. 2015 
contrário, a lei contempla a liberdade de consciência e o livre exercício dos cultos como uma liberdade pública. Ela não diz: 'Escondam esta religião que eu não posso ver...'. Os ultralaicos sempre quiseram impor esta óptica. Eles foram derrotados em 1905, mas hoje eles dominam.

Portanto, sugere-se que a uma suposta declinação do conceito de laicidade no singular se insinuam muitas declinaçôes de laicidades no plural:

Ao plural, porque seguindo as tradições nacionais e regionais, as conjeturas geopolíticas, as mutaçôes sociais dominantes, os períodos sócio-históricos, diferentes tipos de laicidade demonstram-se mais ou menos hegemônicos. A realidade empírica é infinita e mistura ingredientes múltiplos (Baubérot, 2011. Disponível em: <jeanbauberotlaicite.blogspirit.com>. Acesso em: 8-9 nov. 2014.).

Assim sendo, e retornando à afirmação que Diotallevi faz da laicidade francesa como uma "exceção na exceção", faz sentido indagar-lhe, haja vista a heterogeneidade e a complexidade do conceito de laicidade, acerca da pertinência e do valor heurístico dos sentidos outros das laicidades que transcendem, dessa forma, o duplo regime de separatismo tão bem analisado por Diotallevi no texto aqui comentado.

\section{REFERÊNCIAS}

BAUBÉROT, Jean. La représentation de la laïcité comme «exception française». Cosmopolitiques, Paris, n. 16, nov. 2007.

Libertà religiosa e laicità in Francia. Lessico di Etica pubblica, n. 2, 2011. ISSN 2039-2206.

Les laïcités dans le monde. Paris: PUF, 2007.

. La laïcité falsifiée. Paris: La découverte, 2012.

. Histoire de la lä̈cité en France. Paris: PUF, 2010.

Debates do NER, Porto Alegre, Ano I6, N. 27, P. 5I-6I, JAN./Jun. 2015 
Laicité/laicisation. In: AZRIA, Régine; HERVIEU-LEGER, Danièle. Dictionnaire des faits religieux. Paris: PUF, 2010. p. 620-624.

Laïcité et Regard Critique sur la Societé. Website. Disponível em: <jeanbauberotlaicite.blogspirit.com>. Acesso em: 8-9 nov. 2014.

. Jean Baubérot: «N'utilisons pas la laïcité contre l'islam». La Croix, Paris, 10 fev. 2012. Disponível em: <www.la-croix.com/Debats/Opinions/ Debats/Jean-Bauberot>. Acesso em: 2 out. 2012.

BAUBÉROT, Jean; MILOT, Micheline. Lä̈cités sans frontières. Paris: Seuil, 2011.

FRANCE. Ministère de l'Éducation Nationale, de l'Enseignement Supérieur et de la Recherche. Disponível em: <www.education.gouv.fr>. Acesso em: 8-9 nov. 2014.

HADDEN, Jeffrey. Toward desacralizing secularization theory. Social Forces, Oxford, n. 65, p. 587-611, 1987.

ISLAM en France. In: WIKIPEDIA. Disponível em: <www.wikipedia.org/ wiki/Islam_en_France>. Acesso em: 8-9 nov. 2014.

SANCHIS, Pierre. Desencanto e formas contemporâneas do religioso. Ciencias Sociales y Religión, Porto Alegre, ano 3, p. 27-44, 2000.

Recebido em: 10/07/2014

Aprovado em: 05/08/2014 